\title{
Anterior Wall of the Bladder
}

National Cancer Institute

\section{Source}

National Cancer Institute. Anterior Wall of the Bladder. NCI Thesaurus. Code C12334.

The anterior aspect of the bladder wall. 